\title{
Retraction Note: Acute Toxicity of Seven Selected Pesticides (Alachlor, Atrazine, Dieldrin, Diuron, Pirimiphos-Methyl, Chlorpyrifos, Diazinon) to the Marine Fish (Turbot, Psetta maxima)
}

\section{Lazhar Mhadhbi • Ricardo Beiras}

Published online: 21 July 2016

(C) Springer International Publishing Switzerland 2016

Following an investigation by the Editor-in-Chief, this article has been retracted. A complaint received against it indicated that significant sections of the text showed a similarity with the author's own papers published previously. The two papers are:

1. Toxicity of three selected pesticides (Alachlor, Atrazine and Diuron) to the marine fish (turbot Psetta maxima) - Mhadhbi Lazhar, Toumi Hela, Boumaiza Moncef and Aloui Néji, African Journal of Biotechnology, Vol. 11(51), pp. 11321-11328, 26 June, 2012.

2. Toxic Effects of Acute Exposure of Diazinon in turbot (Psetta maxima) Early Life Stage (ELS) Mhadhbi, L. and Boumaiza, M. in the Int. J. Environ. Res., 6(1):139-144, Winter 2012.

The online version of the original article can be found at http://dx. doi.org/10.1007/s11270-012-1328-9.

L. Mhadhbi · R. Beiras

Estación de Ciencias Mariñas de Toralla (ECIMAT), 36331 Vigo, Galicia, Spain

L. Mhadhbi $(\triangle)$

Unité d'Hydrobiologie, Laboratoire de Biosurveillance de

l'Environnement, Faculté des Sciences de Bizerte, Université de Carthage, Zarzouna 7021, Tunisia

e-mail: lazhar@uvigo.es 